was $4.9 \mathrm{nmol} / \mathrm{l}$. Ovulation and regular menstruation were induced by treatment with clomiphene.

More recently, Rao et al reported a 12 year old girl with progressive hirsutism of nine months' duration. ${ }^{5}$ This patient was also premenarcheal with clinical signs of virilisation. Her plasma testosterone concentrations were initially measured on three occasions as being between 4.8 and $9.3 \mathrm{nmol} / \mathrm{l}$. Both ovaries were enlarged on exploratory laparotomy, and bilateral wedge resections of the ovaries were carried out, which showed histological evidence of polycystic ovary syndrome but no tumour. In this patient the testosterone concentrations did not fall after operation, and she was treated successfully with an oral contraceptive.

Thirdly, polycystic ovary syndrome is usually characterised by some enlargement of the ovaries, but is rarely associated with large cysts. The patients in the reports above all had bilaterally moderately enlarged ovaries, but none had individual cysts of the size seen in our patient. This feature also suggests the possibility of associated malignancy, which was not found.

The pathophysiology of polycystic ovary syndrome is still not clearly understood. There are three main approaches to its treatment. Ovulation may be induced by various drugs including clomiphene citrate, human chorionic gonadotrophin, and pure follicle stimulating hormone; the older therapeutic approach of ovarian wedge resection is used much less often today. Antiandrogenic drugs such as cyproterone acetate may be used to reverse the clinical features of masculinisation. Low dose oral contraceptives suppress gonadotrophin secretion and reduce ovarian secretion of androgen; they also reduce the adrenal production of steroids. In this patient an oral contraceptive successfully suppressed both testosterone and gonadotrophin concentrations.

In conclusion, this case and a few previously reported show that isolated polycystic ovary syndrome can be found in virilised premenarcheal girls. In such patients, however, an adrenal source of excess androgen or a virilising tumour of the ovary must be excluded.

\footnotetext{
References

1 Stein IF, Leventhal ML. Amenorrhoea associated with bilateral polycystic ovaries. Am J Obstet Gynecol 1935;29:181-91.

2 Chang RJ, Laufer LR, Meldrum DR, et al. Steroid secretion in polycystic ovarian disease after ovarian suppression by a longacting gonadotrophin-releasing hormone agonist. J Clin Endocrinol and Metab 1983;56:897-903.

3 Prunty FTG, Brooks RV, Dupre J, et al. Virilisation and the human ovary: including observations on the Stein-Leventhal syndrome. Proceedings of the Royal Society of Medicine 1964; 57:529-32.

${ }^{4}$ Richmond SS, Goldstein DP, Dluhy RG, et al. A 13 year old premenarchal female with the Stein-Leventhal syndrome. Fertil Steril 1972;23:508-12.

5 Rao JK, Chihal HJ, Johnson CM. Primary polycystic ovary syndrome in a premenarchal girl: a case report. J Reprod Med 1985; 30:361-5.
}

Correspondence to Dr AT Piesowicz, Queen Mary's Hospital for Children, Carshalton, Surrey SM5 4NR.

Accepted 15 February 1989

\title{
Successful treatment of a harlequin fetus
}

\section{P S WARD AND R D JONES}

Norfolk and Norwich Hospital, Norwich, Norfolk

SUMMARY We report the prolonged survival of a harlequin fetus who was treated with intensive supportive measures, emollients, and oral etretinate.

The Harlequin fetus is the severest of the congenital ichthyoses and is usually considered to be fatal.

\section{Case report}

A baby girl, who weighed $2360 \mathrm{~g}$, was delivered at
38 weeks' gestation after a normal pregnancy. There was no relevant family history.

Her skin consisted of thick, yellow, leathery plaques separated by deep red cracks. There was ectropion of the eyelids and eclabion of the mouth. The ears were flattened and bound to the side of the head. The digits of the hands and feet were flexed and bound together by tight membranes. Examination of a skin biopsy by light and electron microscopy showed changes consistent with the clinical diagnosis of a harlequin fetus.

The baby was nursed in an humidified incubator and fluids were administered via an umbilical artery 
catheter. Fluids were progressively increased to a maximum of $250 \mathrm{ml} / \mathrm{kg}$ per day in order to maintain a normal serum urea. A mixture of equal parts of white soft paraffin and liquid paraffin containing $1 \%$ salicylic acid was applied to the skin every three hours. She was bathed twice daily. Emulsifying ointment and antiseptic solution were added to the water.

After 24 hours she became tachypnoeic and feverish. Arterial blood gases showed $\mathrm{pH} 7.45$, $\mathrm{PaCO}_{2} 3.01 \mathrm{kPa}, \mathrm{PaO}_{2} 7.1 \mathrm{kPa}$, bicarbonate 15.7 $\mathrm{mmol} / \mathrm{l}$, and base excess $7 \cdot 1$. The serum salicylate concentration was $586 \mathrm{mg} / \mathrm{l}$. The salicylate containing emulsion was discontinued and topical treatment was continued with simple white soft paraffin and liquid paraffin.

On the third day oral etretinate, $1 \mathrm{mg}$ three times daily, was commenced. Initially an unstable solution was prepared each day by the hospital pharmacy but later a dry diluent was obtained (Avicel 101, Honeywell and Stain Ltd, Wallington) enabling the production of a stable powder suitable for outpatient use.

Her skin gradually softened and the hard yellow plaques separated, leaving a red scaly surface beneath. The perioral skin became more mobile and by the fifth day she was able to breast feed. Tight bands of skin around the wrists and ankles responded to topical $10 \%$ urea in liquid paraffin applied under an occlusive dressing. Plugs of keratin in the external auditory canals cleared with Cerumol (LAB) ear drops. At two weeks of age the skin was greatly improved and she was able to maintain her body temperature in an open cot. She went home on day 23. Continuing treatment consisted of twice daily baths, topical paraffin emulsion, chloramphenicol and hypromellose eye drops, and oral etretinate.

As the skin improved the frequency of bathing and topical treatment was reduced. The dose of etretinate was halved at 10 months and discontinued at one year. No abnormalities of liver function or renal function were detected during etretinate treatment.

Weight gain was initially poor but subsequently improved, however at 21 months her weight and height were still below the third centile and the head circumference was on the fifth centile. Her developmental progress was within normal limits. The skin was dry, erythematous, and covered in large, thin scales. Ectropion and eclabion had resolved and the membranes binding the digits had disappeared.

\section{Discussion}

The appearance of the harlequin fetus is bizarre and may be abhorent to both parents and professionals. Paediatric textbooks offer an appalling prognosis with death occurring within a few days or weeks. ${ }^{1}$ Paediatricians may therefore choose not to pursue active management.

The skin is thick, inelastic, and permeable. Death is believed to result from excessive fluid loss, inability to feed because of eclabion, and respiratory embarrassment caused by limitation of chest movement. $^{2}$ In order to minimise evaporative water losses our patient was nursed in a humidified incubator and treated topically with paraffin emulsion. The addition of salicylic acid to the emulsion resulted in salicylate toxicity and had to be withdrawn. Despite these measures it was still necessary to provide large volumes of parenteral fluids to maintain normal urea and electrolyte values.

Lawlor and Peiris first used etretinate to treat a harlequin fetus in $1985 .^{3}$ Etretinate is a synthetic retinoid derived from Vitamin A. Its mode of action is unknown but retinoids have been shown to control differentiation and proliferation of keratinising and non-keratinising epithelia. The main systemic side effects are teratogenicity and the development of exostoses with prolonged use. ${ }^{4}$ Dose dependent changes in liver function tests (bilirubin, alkaline phosphatase, and transaminases) have been reported in adults. However, both our patient and that of Lawlor and Peiris had normal values.

The long term outcome of the harlequin fetus is unknown, our case being only the second baby to have survived beyond the first birthday. Lawlor and Pieris published further details of their case when she was 10 months old. ${ }^{5}$ The skin was then dry, erythematous, and ichthyotic. Previously the longest surviving case had been that of Buxman et al who lived until 9 months when he suddenly died. ${ }^{6} \mathrm{He}$ had received emollients and supportive care only.

The death of a harlequin fetus is not inevitable. Aggressive supportive care is probably the single most important part of management. Oral etretinate may be of additional benefit but current experience is very limited.

\footnotetext{
References

' Esterly NB, Solomon LM. Congenital and hereditary disorders of the skin. In: Avery ME, Taeusch HW, eds. Schaffer's diseases of the newborn. Philadelphia: W B Saunders, 1984:868.

2 Kouskoukis C, Minas A, Tousimis D. Ichthyosis congenital fetalis (harlequin fetus). Int J Dermatol 1982;21:347-8.

${ }^{3}$ Lawlor F, Peiris S. Harlequin fetus successfully treated with etretinate. Br J Dermatol 1985;112:585-90.

${ }^{4}$ Glover MT, Peters AM, Atherton DJ. Surveillance for skeletal toxicity of children treated with etretinate. $\mathrm{Br} J$ Dermatol 1987;116:609-14.
} 
${ }^{5}$ Lawlor F, Peiris S. Progress of a harlequin fetus treated with etretinate. J R Soc Med 1985;78:(suppl 11):19-20.

6 Buxman MM, Goodkin PE, Fahrenbach WH, Dimond RL. Harlequin ichthyosis with epidermal lipid abnormality. Arch Dermatol 1979;115:189-93.
Correspondence to Dr PS Ward, Paediatric Department, Addenbrooke's Hospital, Hills Road, Cambridge CB2 $2 Q Q$.

Accepted 20 March 1989

\title{
Effect of dystonic movements on oesophageal peristalsis in Sandifer's syndrome
}

\author{
J W L PUNTIS, H L SMITH, R G BUICK, AND I W BOOTH \\ Institute of Child Health, University of Birmingham
}

SUMmary A 5 year old girl with gross gastrooesophageal reflux had pronounced dystonic neck movements that resolved after fundoplication and resolution of the oesophagitis (Sandifer's syndrome). Oesophageal manometry before operation showed that peristalsis improved when she tilted her head to one side. Dystonic posturing may promote acid clearance from the distal oesophagus.

\section{Case report}

A 5 year old girl was referred with a 12 week history of belching and vomiting, mainly after food. A barium swallow examination was reported to show the presence of a hiatus hernia. Her appetite had decreased appreciably, and she was thought to have lost weight. She vomited about three times a day; occasionally altered blood was present in the vomit. Her general health had been good, although she had an operation for squint, had had grommets inserted, and had a history of urinary tract infections. On physical examination she looked well though pale, and was on the 50th centile for both height and weight. The most striking feature was pronounced neck dystonia with repeated rotation of the neck and tilting of the head towards the left shoulder (fig 1), sometimes associated with bending the upper part of her body to the left. No other abnormalities were found on neurological examination, and the dystonic movements stopped when she was asleep.

\section{INVESTIGATIONS}

Her haemoglobin concentration was $91 \mathrm{~g} / \mathrm{l}$ with a microcytic film, and the platelet count was raised at $680 \times 10^{9} / 1$, suggesting chronic blood loss. Microscopy of her sputum showed fat laden macrophages consistent with recurrent aspiration, and 24 hour oesophageal $\mathrm{pH}$ monitoring confirmed severe gastro-oesophageal reflux, with a reflux index (percentage of time the $\mathrm{pH}$ was less than 4 in the lower oesophagus) of $39 \%$ (normal $<4 \%$ ). A severe ulcerative oesophagitis of the lower half of the oesophagus was found at endoscopy and confirmed by histological examination of biopsy specimens. No hiatus hernia was seen. Oesophageal manometric recordings during $5 \mathrm{ml}$ swallows of water showed low amplitude, slowly propagated, peristaltic waves in the middle and lower oesophagus (fig 2(a)) with a mean amplitude of 47 and $25 \mathrm{~mm} \mathrm{Hg}$, respectively. These increased to means of 74 and $52 \mathrm{~mm} \mathrm{Hg}$ when the patient simulated her dystonic neck posture (fig 2(b)). The mean speed of propagation of peristaltic swallows was $2.5 \mathrm{~cm} / \mathrm{s}$ with the head in the midline, and $4.0 \mathrm{~cm} / \mathrm{s}$ while the head was rotated and tilted towards the left shoulder.

\section{PROGRESS}

She was started on sucralfate $500 \mathrm{mg}$, cisapride $3 \mathrm{mg}$, and ranitidine $15 \mathrm{mg}$, all taken four times a day. Over the next six weeks, however, she continued to vomit and make dystonic neck movements. Repeat endoscopy showed that the severe ulcerative oesophagitis was unchanged, and a Nissen fundoplication was therefore carried out. Three months after operation all her symptoms-including the abnormal posturing-had completely resolved. Further oesophageal manometry was considered ethically unjustifiable.

\section{Discussion}

The association between abnormal movements and gastro-oesophageal reflux with hiatus hernia was first recognised by Sandifer, ${ }^{1}$ and the association of abnormal posturing and oesophagitis without hiatus hernia has also been described. ${ }^{2}$ Characteristic 